\title{
La reforma de los Regímenes de Bienestar en Costa Rica, Chile, Argentina, Brasil y Uruguay
}

\author{
Manuel SÁNCHEz DE Dios \\ Universidad Complutense de Madrid \\ manuesan@ucm.es
}

Recibido: 27-05-2014

Aceptado: 01-10-2015

\section{Resumen}

El objeto de este trabajo es analizar las transformaciones de la política social en América Latina en el contexto de la emergencia de un Estado de bienestar institucional-redistributivo. Para entender los cambios producidos se tienen en consideración las teorías de la reforma institucional y se estudian las transformaciones realizadas en el siglo XX y en los comienzos del siglo XXI para sustituir un régimen de seguridad social de rasgos residuales, basado en la segmentación de las prestaciones y en programas de lucha contra la pobreza, por otro universalista de naturaleza redistributiva. Se valora en particular la evolución reciente de los casos más avanzados en la construcción del Estado de bienestar: Costa Rica, Chile, Argentina, Brasil y Uruguay.

Palabras clave: Estado de bienestar; América Latina; reforma institucional; izquierda latinoamericana; neoliberalismo; neoinstitucionalismo. 


\title{
The Reform of Welfare Regimes in Costa Rica, Chile, Argentina, Brazil and Uruguay
}

\begin{abstract}
The aim of this article is to analyze the social policy in Latin America in a context of emerging welfare states. To understand the changes one takes into consideration the theories about institutional reform and the transformations produced in the XX century and the beginning of the XXI to substitute a social security regime mainly based on segmentation of benefits and on programs to fight poverty by another with an institutional and redistributive nature. The paper pays attention in particular to the path of the most developed welfare states of Latin America: Costa Rica, Chile, Argentina, Brasil y Uruguay.
\end{abstract}

Keywords: Welfare State; Latin America; Institutional Reform; Latin-American Left; Neo-liberalism; Neo-institutionalism.

\section{Referencia normalizada}

SÁnchez de Dios, M. (2015): "La reforma de los Regímenes de Bienestar en Costa Rica, Chile, Argentina, Brasil y Uruguay”, Política y Sociedad, 52 (3), pp. 661-690.

Sumario: 1. Introducción. 2. Teorías de la reforma institucional. 3. Las reformas de la política social en el siglo XX en AL. 4. Dinámica de las reformas por países. 5. Conclusiones. 6. Bibliografía. 


\section{Introducción}

Si bien la comparación de los sistemas de bienestar en América Latina (AL) es muy difícil como señalan Huber y Bogliaccini (2010: 654), desde hace tiempo se han identificado los grandes problemas de la política social latinoamericana. El principal problema para el desarrollo del Estado de bienestar (EB) ha sido la cobertura limitada que tienen los programas de bienestar, por la existencia de un amplio sector laboral informal, por el alto grado de fragmentación de las prestaciones y por la desigualdad del acceso a las mismas (Huber, 1998). La consecuencia es que los diferentes regímenes de política social de AL vienen lastrados por los altos niveles de desigualdad y, en particular, de pobreza de la población. La desigualdad está potenciada, paradójicamente, por el hecho de que la financiación de la política social descansa en grupos que no están protegidos por ella, ya que en parte se financia mediante impuestos indirectos. La pobreza ha sido por mucho tiempo el factor determinante de las políticas reformistas y ha condicionado que buena parte de los programas de política social sean de tipo focalizado, es decir, de naturaleza residual.

En general, se acepta que en AL no se ha desarrollado aún un Estado interventor que garantice un nivel adecuado de prestaciones a la población (Espina, 2008). Huber y Stephens (2012) sostienen que en AL hay que hablar más modestamente de "regímenes de política social", ya que no se han desarrollado plenamente EB similares a los de las democracias avanzadas. Martínez Franzoni (2007) por su parte distingue diferentes "regímenes de bienestar" en AL. Sin embargo Draibe y Riesco (2007) defienden la existencia en algunos de los países latinoamericanos de EB "de rango medio", consecuencia del desarrollo económico alcanzado en la década de 1980.

Filgueira (2007: 14) señala que la configuración de la política social en AL es diferente a la europea, pues ni las comunidades, las familias o la organización de los mercados son similares, ya que AL nunca fue urbanizada ni industrializada con modelos familiares nucleares tradicionales y con mercados laborales formales. También Gough y Therborn (2010) entienden que es imposible hacer una trasposición de las lecciones obtenidas de la industrialización europea a los países en desarrollo, en particular de las relativas al desarrollo del EB. Los mercados laborales informales han sido un factor distintivo de AL, ya que no permiten disfrutar de las prestaciones sociales a la mayor parte de los trabajadores (Milanovic y Muñoz Bustillo, 2008: 36) y, de hecho, una gran parte de los trabajadores protegidos por la seguridad social no han podido desarrollar toda su actividad en el sector formal (Huber y Steghens, 2102: 67). Empero, recientemente se está retomando el análisis de las políticas de bienestar en AL a partir de las teorías del EB formuladas para los países industriales avanzados; así se deduce del concepto del "Estado de bienestar del Tercer Mundo" de Kurtz, (2002), la perspectiva teórica de "los Estados de bienestar emergentes" que apoya Gough, (2004) y la de los "Estado de bienestar de desarrollo" de Riesco (2009). Tales trabajos se centran en 
explicar, en unos casos, los cambios en el ámbito de la industrialización y urbanización y sus consecuencias en el desarrollo de las políticas sociales y, en otros casos, los cambios de los regímenes políticos (democratización), en la distribución del poder político y en la formación de coaliciones políticas (Huber y Bogliaccini, 2010; Huber y Stephens 2012; Pribble, 2013). Esta es la línea en la que se plantea el presente trabajo.

El concepto de EB es un concepto acuñado por la política comparada que se refiere a la naturaleza de la intervención del Estado para la distribución del producto social en una economía de mercado (Sánchez de Dios, 2012: 73 y ss.). Se ha generado en las sociedades industriales como consecuencia del desarrollo económico y el de los grupos de presión, en particular del movimiento obrero organizado partidario del reformismo político. Se pueden identificar dos modelos más o menos polares de EB: el residual y el institucional-redistributivo. En el primero, que es postulado por los neoliberales, la intervención del Estado se orienta exclusivamente a establecer un "nicho de seguridad" (safety net) para aquellos que no puedan alcanzar el bienestar por sí mismos, ya que deben ser las fuerzas del mercado las que organicen la economía. En el segundo, que es el defendido por los keynesianos, la intervención del Estado ha de combatir los fallos del mercado, en particular en el mercado de trabajo, y ha de tener funciones redistributivas para desarrollar la "ciudadanía social", es decir, para garantizar un bienestar básico e igual a toda la población (universal); ha de estar financiado desde el presupuesto estatal mediante un régimen fiscal progresivo, así la redistribución queda institucionalizada. Todavía se pueden identificar otros modelos complementarios. Uno es el de base corporativa de tipo bismarckiano, que configura unas políticas de bienestar orientadas por la previa incorporación de los individuos al mercado de trabajo y por la aportación de cotizaciones con las que se financian las prestaciones que perciben. En este la redistribución no está institucionalizada. Otro, en fin, es el de tipo socialdemócrata que persigue la construcción del socialismo a través del EB universalista y redistribuidor que desmercantiliza la fuerza de trabajo (Esping-Andersen, 1990).

AL ha seguido el patrón de las sociedades industriales pero bajo parámetros diferentes, ya que ha tenido un desarrollo industrial desequilibrado que ha determinado también una forma desequilibrada de las políticas sociales. Es opinión generalizada que la formación del EB en AL, en particular donde este está más avanzado, ha seguido el patrón bismarckiano o corporativo-conservador, siendo el universalismo de las políticas de bienestar un objetivo en el desarrollo de la política social.

La idea de un "universalismo básico" para AL ha sido defendida desde el Banco de Desarrollo Interamericano como un sistema de protección social desde el Estado que garantice a todos los ciudadanos un conjunto de servicios y transferencias esenciales. Pero esta idea se puede precisar en un sentido institucional y redistributivo al dar cuenta de las reformas pendientes para superar el modelo corporativo, como se ha hecho desde el ámbito académico (Mesa Lago, 1982: 105 y ss.; Huber, 1998: 181; Martínez Fanzoni, 2007: 89; Filgueira 2007). Un resumen de tales propuestas de reforma es lo 
señalado por Pribble (2013: 172) que entiende que el universalismo ha de basarse en una cobertura pública para todos los ciudadanos de servicios sociales esenciales como educación preescolar, básica y secundaria, sanidad, un salario mínimo por la actividad laboral y una renta mínima en caso de jubilación, desempleo o incapacidad. Además de que tales prestaciones han de ser administradas de forma transparente (no discrecional), han de ir orientadas a combatir la segmentación y se han de financiar de manera igualitaria y sostenible.

Cuadro 1: Indicadores Socioeconómicos de la CEPAL

\begin{tabular}{|c|c|c|c|c|c|c|c|}
\hline & $\begin{array}{l}\text { Gasto } \\
\text { social / } \\
\text { PIB }\end{array}$ & $\begin{array}{l}\text { G.en seg. } \\
\text { social / } \\
\text { PNB }\end{array}$ & $\begin{array}{l}\text { Gasto en } \\
\text { educación / } \\
\text { PNB }\end{array}$ & $\begin{array}{l}\text { Gasto en } \\
\text { sanidad / } \\
\text { PNB }\end{array}$ & $\begin{array}{l}\text { Índice } \\
\text { Pobreza }\end{array}$ & $\begin{array}{l}\text { Trabajo } \\
\text { informal }\end{array}$ & $\begin{array}{c}\text { PIB / } \\
\text { habitante }\end{array}$ \\
\hline & \multicolumn{4}{|c|}{2010} & \multicolumn{3}{|c|}{2011} \\
\hline Argentina & $27,8^{\beta}$ & $12,9^{\beta}$ & $6,7^{\beta}$ & $6,21^{\beta}$ & $5,7^{\Omega}$ & 38 & 6784,3 \\
\hline Bolivia & 12,4 & 4,7 & 6 & 1,5 & 36,3 & 60 & 1239,0 \\
\hline Brasil & $27,0^{\beta}$ & $14,0^{\beta}$ & $5,9^{\beta}$ & $5,2^{\beta}$ & 20,9 & 39 & 5723,9 \\
\hline Chile & 15,6 & 6,9 & 4,4 & 3,9 & 11,0 & 26,7 & 9073,7 \\
\hline Colombia & 13,6 & 7,8 & 3,1 & 1,9 & 34,2 & 59,9 & 4115,8 \\
\hline Costa Rica & 22,9 & 6,6 & 7,5 & 6,6 & 18,8 & 36,2 & 5492,2 \\
\hline Ecuador & 9,8 & 1,9 & 5,5 & 2 & 35,3 & 55 & 3230,4 \\
\hline El Salvador & $13,0^{\beta}$ & $4,3^{\beta}$ & $3,8^{\beta}$ & $4,0^{\beta}$ & $46,6^{\alpha}$ & $55^{\alpha}$ & 2976,7 \\
\hline Guatemala & $8,0^{\beta}$ & $1,2^{\beta}$ & $3,5^{\beta}$ & $1,4^{\beta}$ & $54,8 \gamma$ & $55,1 \gamma$ & 2303,9 \\
\hline Honduras & 12,0 & 0,6 & 7,6 & 3,4 & $67,4^{\alpha}$ & $50,8^{\alpha}$ & 1543,9 \\
\hline México & 11,3 & 3,1 & 3,8 & 2,7 & $36,6^{\alpha}$ & $44,2^{\alpha}$ & 8444,1 \\
\hline Nicaragua & $13,0^{\beta}$ & s.d & $6,0^{\beta}$ & $4,0^{\beta}$ & $58,3^{\beta}$ & $43,4^{\beta}$ & 1289,1 \\
\hline Panamá & $10,5^{\beta}$ & 1,6 & $4,0^{\beta}$ & $2,2^{\beta}$ & 25,3 & 31,5 & 7259,2 \\
\hline Paraguay & 11,0 & 3,8 & 4,6 & 2,3 & 49,6 & 53,3 & 1771,9 \\
\hline Perú & 9,9 & 3,4 & 3,1 & 1,6 & 27,8 & 58,8 & 4052,4 \\
\hline R. Dominicana & 7,3 & 1,8 & 2,4 & 1,7 & 42,2 & 50,6 & 4918,8 \\
\hline Uruguay & $23,3^{\beta}$ & $11,6^{\beta}$ & $5,1^{\beta}$ & $4,9^{\beta}$ & 6,5 & 34,8 & 7189,8 \\
\hline Venezuela & 17,3 & 7,1 & 5,3 & 3,4 & 29,5 & 51,6 & 6165,8 \\
\hline
\end{tabular}

Notas: Se resaltan los mejores datos; ${ }^{\alpha}: 2010 ;{ }^{\beta}: 2009 ;^{\Omega}:$ Área urbana;

Fuente: CEPALSTAT.

La consecución de un universalismo de tales características en AL es difícil debido a las grandes limitaciones de cobertura de los programas sociales, a la gran desigualdad provocada por estas y, además, a los altos niveles de pobreza. Empero, el proceso de reforma de la política social ha avanzado desde la década de 1990. Es por ello que este trabajo tiene como objeto analizar la naturaleza de las reformas realizadas en los 
últimos años en los EB más desarrollados de AL. Para esto se adopta una perspectiva histórica desde la que se pueden considerar los procesos de reforma, los actores intervinientes y los momentos de cambio, así como las diferentes paths o trayectorias seguidas en cada caso.

En este trabajo se consideran las reformas de los últimos decenios en los cinco países que han alcanzado un mayor desarrollo del EB: Costa Rica, Chile, Brasil, Argentina y Uruguay. La selección de estos países sigue el criterio académico de Huber (1998: 147), Huber y Stephens (2012: 77), Filgueira (2007: 14) y Martínez Franzoni (2007), si bien estos últimos consideran que Brasil está menos avanzado al tener una alta tasa de dependencia. También aparecen estos países en los datos de la CEPAL como los que han alcanzado mayor nivel en gasto público social en relación al PIB en 2010, en general y para cada uno de los grandes sectores (ver cuadro 1), y tienen, además, un elevado nivel de renta per cápita, que determina la cantidad real de recursos que se pueden destinar al gasto social. Estos países son los que, junto a Panamá, tienen los menores niveles de pobreza en la región y una menor tasa de "trabajo informal", que es uno de los principales factores determinantes de la pobreza, la desigualdad y la falta de desarrollo de la seguridad social, y se puede medir a través del indicador de la CEPAL de "población urbana ocupada en sectores de baja productividad del mercado de trabajo".

\section{Teorías de la reforma institucional}

Siendo el objeto de este trabajo los cambios de los regímenes de seguridad social en América Latina, se hace preciso definir el marco conceptual de la reforma institucional desde la perspectiva del análisis neoinstitucional. La conexión entre este análisis y el desarrollo del EB se debe a que las políticas de bienestar tienen una configuración institucional en cuanto que son procedimientos y organizaciones que dan estructura al sistema de protección social. Como han apuntado Pierson (2000) o Mahoney y Thelen (2012) las estructuras institucionales traducen momentos de cambio y ruptura o de emergencia de nuevas fuerzas, así como acuerdos o formación de coaliciones distributivas. Tal es la perspectiva que manejan entre otros Pribble (2013) y Huber y Stephens (2012) en el estudio del EB en AL. La reforma institucional es un campo de debate en la actualidad en la ciencia política entre los dos paradigmas dominantes del análisis neotinstitucional: el institucionalismo histórico y el institucionalismo racionalista.

La principal diferencia entre ambos enfoques radica en la consideración que tienen de la naturaleza de las instituciones; de aquí resulta el concepto que se sigue de reforma institucional. Desde la perspectiva de la teoría de la elección racional (TER) las instituciones sirven a los intereses de los actores (Eriksson, 2011: 145) y se conforman como modelos de comportamiento regulares que reflejan un equilibrio óptimo o un subjuego de soluciones perfectas a los dilemas de la acción colectiva, que es estable porque los 
actores no pueden mejorar sus posiciones abandonando su patrón de comportamiento (Hall, 2010: 204; Shepsle 2008: 26). Las instituciones, así, son creadas para una función y se mantienen porque establecen un equilibrio que nadie puede o quiere modificar (equilibrio Nash). El equilibrio entre las estrategias de los actores explica la estabilidad de las instituciones y que una vez creadas tiendan a ser estables. Siguiendo esta línea de razonamiento y desde la perspectiva de la teoría del dilema del prisionero, se puede decir que las instituciones se crean para potenciar la cooperación, y así se explica la existencia del propio Estado y su desarrollo como Estado de bienestar; además, las instituciones que conforman las políticas de bienestar se consideran como un bien público.

Desde la perspectiva de la TER el cambio institucional implica un movimiento entre dos estados de equilibrio. El cambio es necesariamente producido por una modificación en la distribución de preferencias entre los actores y, lógicamente, tiene que ser debido a un factor externo. Es decir, como las instituciones son un mecanismo de coordinación que producen y mantienen un equilibrio particular basado en que para cada actor el arreglo institucional existente es la mejor respuesta, el cambio tiene que tener un origen exógeno (Eriksson, 2010: 161). Este es el punto de vista de la teoría de la "lógica del industrialismo" para explicar la emergencia del EB. Según esta teoría la modernización económica es el factor (exógeno) que hace necesaria la política social, porque las transformaciones provocadas por la movilidad social, la urbanización, la formación de las clases medias y la cultura individualista destruyen las instituciones sociales tradicionales. Al mismo tiempo la política social y el desarrollo del EB favorecen el proceso de desarrollo económico. Como explica Riesco (2007:43) en AL el gasto social y las instituciones de política social se han expandido al mismo tiempo que se ha producido el desarrollo económico a lo largo del siglo XX. Este planteamiento, por otra parte, es el que se formula en la Declaración de Desarrollo del Milenio o en la Agenda Social Europa, ambos del año 2000, y es también propugnado por el Instituto de Investigación para el Desarrollo Social de la ONU que promueven el desarrollo humano, la inclusión y la cohesión social vinculados al "desarrollo social" (Riesco, 2007:3).

Ahora bien, la "estática comparativa" que se da en el planteamiento del cambio institucional de la TER, no permite profundizar y explicar el proceso del cambio o, en otros términos, no permite realizar un análisis dinámico del cambio institucional, ya que se centra en constatar y explicar las situaciones de equilibrio producido por el cambio. Sin embargo, esto es diferente desde la perspectiva del institucionalismo histórico (IH), para el que las instituciones están orientadas a resolver problemas y determinan los objetivos y las estrategias de los actores. La cuestión clave que diferencia al IH del institucionalismo de la TER se refiere a cómo se forman las preferencias de los actores. Mientras que para la TER las preferencias de los actores son fruto de factores exógenos, como acabamos de ver, para el IH son factores endógenos ligados a las propias instituciones los que los determinan (Eriksonn, 2012: 154; Ostrom, 1995: 89). 
En el ámbito del IH la teoría del path dependence o de las "trayectorias dependientes" (Pierson, 2000) también resalta la persistencia y estabilidad de las instituciones debidas a la "retroalimentación positiva", o auto-reforzamiento, que es consecuencia de los beneficios de seguir un esquema que ya está en marcha y de los costes de abandonarlo. Esto explica el equilibrio institucional. Sin embargo, también tiene en cuenta que hay "coyunturas críticas" en que se producen cambios institucionales, que suponen modificaciones en la trayectoria seguida por las instituciones para adaptarse a las condiciones ambientales. Así, se considera que las trayectorias que siguen las instituciones son periódicamente alteradas e interrumpidas por la necesidad de realizar intervenciones o llevar a cabo elecciones entre situaciones alternativas en momentos de ruptura, de colisión institucional o de vacío institucional. Es decir, la perspectiva general del path dependence señala que las instituciones operan en un marco de equilibrio que periódicamente es interrumpido (punctuated equilibrium), dando lugar a modificaciones en su trayectoria de desarrollo; estos son los branchig points o puntos de ramificación que están en el origen del cambio institucional. (Sánchez de Dios, 2001: 99). Son situaciones que cabe considerar como momentos de ruptura de un sistema institucional viejo y la adopción de uno nuevo. Ejemplos de este tipo de reforma de base endógena son los cambios requeridos por desequilibrios en la financiación de la seguridad social o los orientados a corregir la desigualdad causada por su fragmentación y estratificación corporativa. En todo caso hay que tener en cuenta que el cambio institucional siempre tiene una naturaleza incremental, en el sentido de que modifica y transforma una estructura a largo plazo (North 1990:89). Como veremos, esta ha sido una característica del desarrollo del EB en AL.

Ahora bien, frente a una reforma discontinua o radical, como la apuntada más arriba, cabe identificar otra de carácter gradual, mediante ajustes continuados de tipo marginal (North, 1990:101). Esta última ha sido la dominante históricamente, y mediante la que las sociedades han ido evolucionando. Este segundo tipo de reforma se basa en considerar a las instituciones como estructuras de "distribución de autoridad" que generan un reparto asimétrico del poder entre los distintos grupos. Es decir, el cambio está originado por las propiedades de las instituciones, es fácilmente observable y en la práctica da lugar a diferentes tipos de reformas (Mahoney y Thelen, 2010). Desde esta perspectiva se considera que las instituciones no son tanto estructuras cooperativas como distribuidoras del poder político que, además, tienden a reforzar la distribución existente. Las instituciones, por ello, están basadas en una tensión, en un equilibrio inestable, porque inevitablemente determinan y sacan a la luz los recursos que se distribuyen entre los actores. Esto se pone en evidencia respecto de los recursos de alto valor económico, como son los que conlleva la política social. Es por esto por lo que los actores tienden a definir las instituciones de acuerdo con sus intereses y los más poderosos imponen las instituciones que refuerzan sus objetivos. Pero también hay instituciones que no reflejan exclusivamente los objetivos de un grupo y pueden ser el resultado de 
compromisos más o menos ambiguos entre grupos, los cuales solo pueden coordinarse por medio de las instituciones, cosa que es muy frecuente.

Desde esta perspectiva "distributiva" la reforma institucional tiene un carácter dinámico que se explica porque, al ser las instituciones resultado de acuerdos basados en coaliciones abiertas, siempre están sujetas al cambio. Quienes están favorecidos por el arreglo institucional tenderán a perpetuarlo y tratarán de resolver a su favor las posibles ambigüedades del acuerdo mediante la movilización política. Ejemplo de ello son las coaliciones que se forman en los regímenes de seguridad social no igualitarios de $\mathrm{AL}$ donde los sectores privilegiados tratan de bloquear las reformas redistributivas. Otro ejemplo de ello es que los partidos de izquierda son más reformistas cuando son partidos de masa, con estrechos lazos con los sindicatos y otras organizaciones populares porque, a diferencia de los partidos de base electoral-profesional elitistas y clientelares, desarrollan un planteamiento más programático orientado a la redistribución (Huber y Stephens, 2012: 254). Una importante fuente de cambio institucional es la que viene de las alteraciones en la balanza de poder entre los actores, como son, por ejemplo, los producidos por un reajuste de las fuerzas políticas tras unas elecciones, porque modifican la capacidad de negociación de los actores.

El planteamiento distributivo es el que sigue la teoría de los "recursos de poder", según la cual el EB o la política social es un recurso para los asalariados. Así, los derechos sociales, la seguridad de los ingresos, la igualdad y la erradicación de la pobreza que promueve un EB universalista, son pre-condiciones para la movilización del movimiento obrero (Esping Andersen, 1990). Este es el punto de vista de Huber y Stephens (2012: 19), para los que la desigualdad material determina la desigualdad política entre los ciudadanos y consideran que los intereses de clase se construyen socialmente y, en consecuencia, los sindicatos y los partidos no solo movilizan sino que configuran y dan forma a las opiniones de los votantes y sus preferencias sobre la redistribución. La existencia de democracia y de las organizaciones de trabajadores (sindicatos y partidos) que pueden actuar en un marco institucional es, por tanto, una condición para el desarrollo del EB.

También este es el punto de vista de la teoría de los "buscadores de rentas" (rent seeking) en el marco de la TER, que considera que la intervención del Estado provoca la aparición de un comportamiento de este tipo, por ejemplo, el de los grupos de presión como los sindicatos que reclaman una intervención que favorezca a sus intereses particulares, sectoriales y no al interés general. En contraposición con el planteamiento anterior, en este se considera, siguiendo el análisis neoliberal, que tal comportamiento bloquea y distorsiona el adecuado funcionamiento del mercado y con ello el desarrollo económico y social en cualquier sociedad (Hindmoore 2006: 156).

Si dejamos a un lado la cuestión del origen del cambio institucional, los dos planteamientos (TER-IH) no parecen excesivamente contradictorios, pues las reformas siempre concluyen en nuevos equilibrios que conllevan una nueva distribución del po- 
der y de los recursos. De hecho, se puede identificar un ámbito común entre ambos enfoques, como es el análisis de la formación de coaliciones reformistas y la manera (vía negociación) en que establecen la agenda. También cabe considerar los costes de oportunidad que las reformas tienen para los actores reformistas como es, por ejemplo, el rechazo sindical que puedan tener las propuestas de gobiernos de izquierda que modifiquen un statu quo que beneficie a ciertos sectores sindicales; igualmente cabe valorar la capacidad de los actores para superar las dificultades que entraña movilizar al electorado en apoyo de las estrategias de cambio. Finalmente, considerando la reforma como un juego de coordinación en que todos ganan, por ejemplo cuando se produce la expansión del gasto social, cabe identificar cómo se distribuye la ganancia (Hall, 2009).

\section{Las reformas de la política social en el siglo XX en AL}

Un nuevo tipo de Estado interventor para promover reformas económicas tomó fuerza en AL tras la crisis de 1929, pues los gobiernos se vieron obligados a estimular la producción interna. Desde entonces se produjo una expansión económica desarrollista, en particular a partir de la década de 1960, resultado de políticas deliberadamente proteccionistas que fueron articuladas e implementadas bajo la estrategia de "sustitución de las importaciones". Esta estuvo acompañada de grandes migraciones a zonas urbanas, del desarrollo de un nuevo sector empresarial y unas nuevas elites burocráticas civiles y militares vinculadas a las nuevas clases medias (Dribe y Riesco, 2007: 45)

Vinculada al desarrollo económico se produjo una expansión de la seguridad social entre las clases medias urbanas, empleados y obreros, que se configuraron como una base social y electoral en apoyo de la misma. La mayor parte de las instituciones de política social fueron creadas en este periodo, de tal forma que a mediados de la década de 1970 en los países pioneros de Argentina, Brasil, Chile y Uruguay se había expandido la cobertura en seguridad social y sanidad a la mayor parte de la población. Tal sistema permitió, además, que los subsidios alcanzaran un buen nivel, porque los empresarios pudieron transferir el elevado coste de las contribuciones con que se financiaba la seguridad social a los consumidores en mercados que estaban protegidos (Huber, 1998: 144). También los Gobiernos se financiaron con los impuestos al comercio exterior y sin necesidad de gravar a los grupos dominantes y privilegiados, ni realizar tampoco subidas de los impuestos sobre la renta. Por esta razón el sistema fiscal quedó estructuralmente desequilibrado y debilitado, convirtiéndose más tarde en un problema en la etapa de las reformas neoliberales.

La protección social se basaba en la lógica de seguro obligatorio y los que no estaban empleados y no pagaban cotizaciones carecían de protección. La trayectoria (path) de desarrollo del EB en AL fue que a los grupos privilegiados y situados estratégicamente en la actividad económica inicialmente protegidos se les fueron sumando nuevos 
grupos, pero ello sin modificar los generosos sistemas de protección previamente establecidos. Así, el ejército, los miembros de la judicatura y los altos funcionarios consiguieron la mejor protección social; en un segundo lugar los profesionales y empleados, y en un tercer lugar los obreros sindicados del ámbito urbano y en las plantaciones agrarias. En consecuencia, se acabó formando un sistema estratificado y fragmentado de tipo corporativo, en el que la seguridad social tenía un carácter regresivo en la perspectiva de la distribución de la renta y la riqueza entre la población. (Mesa-Lago, 1983: 91; Huber y Stephans: 2012: 76; Carrera y Muñoz de Bustillo, 2009: 86).

En suma, la formación y la reforma gradual de la política social tuvo como resultado un juego de suma cero en el que los sectores urbanos mejor organizados ganaron en la redistribución que permitió su expansión a expensas de los empleados autónomos, los desempleados y los trabajadores rurales que la financiaron. Por ello al comienzo de la década de 1980 la pobreza alcanzó unos niveles muy elevados en todo el continente y la distribución de ingresos (la igualdad) estaba entre las peores a nivel mundial.

La crisis económica que comenzó en 1982 fue el momento de una "coyuntura crítica" que ha producido una modificación en la trayectoria de desarrollo de los EA en AL al provocar una transición económica (Martínez Franzoni, 2007: 34). La crisis introdujo dificultades financieras a la política social, en particular en los EB menos desarrollados, acentuando el desequilibrio fiscal de los sistemas de seguridad social (Huber, 1998: 140 y ss). Junto a la incapacidad del Estado para financiarse, se produjo una inflación galopante que erosionaba las pensiones y todo el sistema de protección, al mismo tiempo que se pusieron en evidencia otros problemas, como el hecho de que los fondos de la seguridad social se habían invertido de manera deficiente o se habían gastado en otros propósitos, los empresarios trataban de evadir o tardaban en pagar las contribuciones, los costes sanitarios habían sufrido una escalada y, por último, los costes administrativos habían alcanzado valores exorbitantes.

Poco después la crisis de la deuda puso de manifiesto que el modelo económico de "sustitución de importaciones" había llegado a su límite y se precisaba una estabilidad macroeconómica y el control de la inflación mediante disciplina fiscal y monetaria (Huber y Stephens, 2012: 206). A ello se sumaron las políticas de estabilización (de ajuste estructural) impuestas por el FMI y el Banco Mundial para equilibrar las balanzas de pagos. Es decir, que al desequilibrio estructural que desde la década de 1980 arrastraba la seguridad social, se añadieron las políticas restrictivas del gasto público de la década de 1990.

Debido a estas condiciones se abrió un periodo de reformas bajo la conocida expresión de "la reforma del Estado" del Consenso de Washington, inspiradas por las propuestas neoliberales del FMI y de la Agencia de los EE.UU para el Desarrollo Internacional e impulsadas por los gobiernos de M. Thatcher en RU y R. Reagan en USA, tanto en el ámbito de la política económica como de la política social. Junto a la reducción de gasto público se promovió la liberalización del mercado de capitales, una privatización de las empresas estatales y la relajación de las regulaciones e incentivos 
para la inversión directa extranjera. Además se favoreció un cambio de trayectoria en la política social basada en una mayor intervención de la iniciativa privada en la financiación y la provisión de seguridad social y de los servicios sociales. La principal recomendación de las citadas instituciones internacionales fue la privatización de los sistemas de pensiones y dejar en manos del sector privado la provisión de la educación y la sanidad. El Estado únicamente se encargaría de las transferencias y servicios para los más necesitados, es decir, de crear "safety nets" para los extremadamente pobres. El objetivo era promover el crecimiento económico por encima de otras consideraciones (Carrera y Antón, 2008: 45)

Las políticas neoliberales se implementaron por unas nuevas coaliciones de gobierno sobre la base de una renegociación del contrato social legado por el periodo anterior, es decir, sobre la base de una nueva distribución institucional del poder en el que se había producido un retraimiento de las organizaciones sindicales. Las reformas se llevaron a cabo en dos oleadas. Inicialmente por gobiernos autoritarios, como en la dictadura chilena de Pinochet a mediados de la década de 1970, que estaban orientadas a desmantelar los EB. Se caracterizaron, además, por debilitar y reprimir a las organizaciones y partidos de izquierda. Tales gobiernos fueron posteriormente desestabilizados por una crisis generalizada de la deuda pública que había alcanzado grandes dimensiones. La segunda oleada se dio con gobiernos democráticos en la década de los $80 \mathrm{y}$ 90, como en México, Brasil o Argentina, que también fueron afectados por la crisis de la deuda. Los recortes de gasto social en la segunda oleada no fueron tan elevados y en muchos casos se trató de restablecer las instituciones de bienestar que habían sido reducidas anteriormente (Bribe y Riesco, 2007: 55).

La mayor parte de los países latinoamericanos, incluidos los cinco que consideramos en este trabajo, se vieron obligados a acudir a la financiación del FMI y a aceptar los programas de austeridad. Las políticas neoliberales tuvieron el efecto de producir la llamada "década perdida" de 1990, porque su resultado fue la desindustrialización de los países. La elevación del desempleo y la caída de los salarios que esta produjo, así como la reducción de transferencias de la seguridad social, provocaron un fuerte incremento de la pobreza y de la desigualdad. El factor más determinante a este respecto fue el crecimiento de la informalidad en el mercado de trabajo, habida cuenta de que el sistema de protección social estaba organizado desde la perspectiva corporativa y porque los seguros de desempleo no existían, y donde los había cubrían a un pequeño porcentaje de trabajadores (Carrera y Muñoz de Bustillo, 2009:87). Por otra parte, los programas de lucha contra la pobreza (safety net) apenas estaban desarrollados (Huber y Stephens 2012: 175).

Con el cambio de siglo el enfoque del Consenso de Washington empezó a derrumbarse al comprobarse que el modelo neoliberal había fracasado en sus promesas, en particular en el ámbito de la política social. La privatización de los servicios de bienestar quedó totalmente descartada por ineficiente. De hecho, actualmente el Banco Mun- 
dial ha abandonado la defensa del modelo chileno de pensiones y lo ha sustituido por el modelo sueco. También el descontento popular con las políticas neoliberales ha llevado al triunfo de los partidos de centro-izquierda como el Partido de los Trabajadores en Brasil, el Frente Amplio en Uruguay, la Concertación en Chile, el PLN en Costa Rica o el Partido Justicialista de los Kirchner en Argentina. Los nuevos gobiernos han promovido un EB neo-desarrollista (Riesco, 2007) que se apoya en nuevas regulaciones y en una reconstrucción del sector público. Sin embargo, el path neoliberal ha dejado un legado que tiene mucho peso al haberse creado una constelación de intereses y una gran industria en el sector privado en torno a la política social que dificulta el desarrollo de las políticas redistributivas de los gobiernos de izquierda.

\section{Dinámica de las reformas por países}

Al considerar cada caso vamos a tener en cuenta el path o trayectoria histórica, así como las últimas reformas, destacando la distribución de poder que las impulsan y las situaciones de equilibrio generadas. Para valorar mejor los resultados obtenidos en la institucionalización del EB en cada caso vamos a tomar en consideración la evolución de los indicadores de la CEPAL entre 1990 y 2010 relativos al gasto social como porcentaje del PNB y sus componentes (sanidad, educación y seguridad social), además de las tasas de trabajo informal y de pobreza.

1.- Costa Rica es un caso de éxito en el desarrollo de la política social. Desde la década de 1940, con los gobiernos socialdemócratas del Partido de Liberación Nacional y apoyado en un grupo de expertos reformistas, se implantó un modelo bismarckiano (Barahona, Güendel y Castro, 2007: 335). Se creó un sistema de seguridad social unificado mediante la Caja Costarricense de Seguro Social (CCSS) al que están afiliados obligatoriamente todos los trabajadores del sector público y privado. Se facilitó la institucionalización de la política social mediante el acceso universal de los ciudadanos a la educación y la sanidad y estableciendo el universalismo de la seguridad social en la década de 1960, con un sistema integrado de sanidad a través de CCSS desde 1976. Los programas de lucha contra la pobreza comenzaron en 1971. Así, la década de 1970 es descrita en Costa Rica como la década dorada de la política social.

La crisis de la deuda de 1982 puso en evidencia las debilidades del modelo económico, pues el país era dependiente del capital exterior para financiarse. La crisis provocó una caída del 10\% del PNB per cápita en dos años, con un fuerte aumento del desempleo. Después del ajuste estructural orientado a la liberalización exterior, en la década de 1990 se produjo un punto de inflexión en la configuración de la política social, pero no fue un branching point ya que no se llegó a modificar la trayectoria inicial al no alterarse sustancialmente la distribución institucional del poder, ya que se 
han ido alternado gobiernos del PLN y del Partido de Unidad Social Cristiana (PSUC) (Huber, 1998: 175). Desde el primer momento del gobierno Calderón entre $1990 \mathrm{y}$ 1994 del PSUC, se reforzaron los mecanismo de lucha contra la pobreza vía transferencias. Posteriormente, con el gobierno Figueres del PLN, entre 1994 y 1998, se amplió el gasto en educación y sanidad. También se aprobó una enmienda constitucional que estableció el objetivo del 6\% del gasto público en educación, que ha lanzado el gasto social en este campo, como se puede ver en el gráfico 1. En el comienzo de la crisis se creó un Consejo Social para definir las prioridades de la política social, que ha estado activo intermitentemente, y también se definieron nuevos derechos sociales para niños, adolescentes, jóvenes, mujeres, ancianos y discapacitados. En 2000 se aprobó la Ley de Protección de los Trabajadores, que estableció un sistema de pensiones con múltiples pilares, permitiendo el desarrollo de un sistema privado complementario. En consecuencia, a partir de 1993 el gasto social se ha ido recuperando.

Los gobiernos del PUSC se han manifestado partidarios del sector privado en la gestión de los servicios sociales, mientras que los del PLN han estado más orientados a la universalización de la política social. Es por esto que el gobierno del PLN a partir de 2006 ha llevado a un incremento del gasto social, revalorizando las pensiones y los programas de transferencias condicionadas, en particular para jóvenes, si bien parece que el principal problema con el que se enfrenta Costa Rica es el de obtener suficientes ingresos fiscales (Huber y Stephens, 2012: 194).

En Costa Rica se mantiene una alta tasa de empleo informal (más del 40\%), con polarización del mercado laboral, que no se ha reducido a lo largo de los últimos 20 años, como se ve en el grafico 1. En estos años la tasa de población bajo la línea de pobreza ha caído hasta estabilizarse por debajo del 20\%. El Fondo de Desarrollo Social y Asignaciones Familiares es el encargado de gestionar los recursos para la lucha contra la pobreza, con un gasto en torno al 1,5\% del PIB, que se distribuye principalmente a través del gasto en educación. Es aquí donde ha crecido muchísimo el gasto social, pasando del 4,5\% en el 2000 al 7,3\% del PIB en 2011. Las reformas más relevantes de la última década para el control del gasto social se han dado en el ámbito de la gestión, al introducirse las técnicas de la "nueva gestión pública" (Barahona, Güendel y Castro, 2007: 340), aunque en el cuadro se puede observar un proceso de reducción de la pobreza que es parejo a un incremento del gasto social.

Costa Rica ha sido el único país que en mucho tiempo ha desarrollado un path socialdemócrata en AL, sin que las diferentes coyunturas, como han sido restricciones en la financiación de la seguridad social debida a la crisis de los 80 y la liberalización económica producida desde entonces para la promoción de las exportaciones, lo hayan modificado (Huber, 1998: 175). En Costa Rica la prestación pública de servicios es muy alta y el componente solidario está presente en la salud y en las pensiones. Hay un EB universalista en pensiones y sanidad que opera con criterios de equidad y solidaridad, si bien las pensiones contributivas solo cubren al $50 \%$ de la población 
activa (Martínez Franzoni: 38 y ss). Los factores fundamentales del equilibrio en que se fundamenta el desarrollo del EB en Costa Rica han sido la competición electoral y la existencia de un partido socialdemócrata, el PLN, como partido de gobierno (Huber y Stephens, 2012: 93).

GrÁFICO 1: INDICADORES DE COSTA RicA 1990-2011

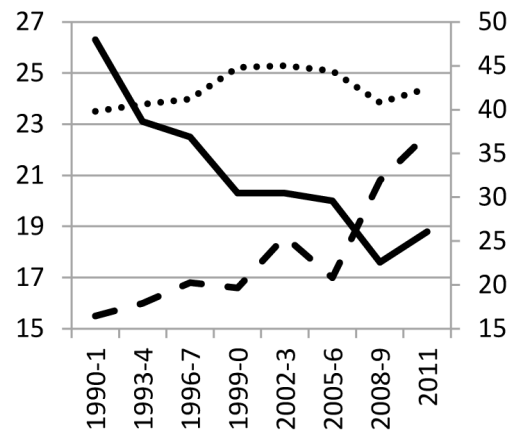

- G. social

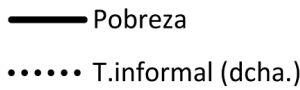

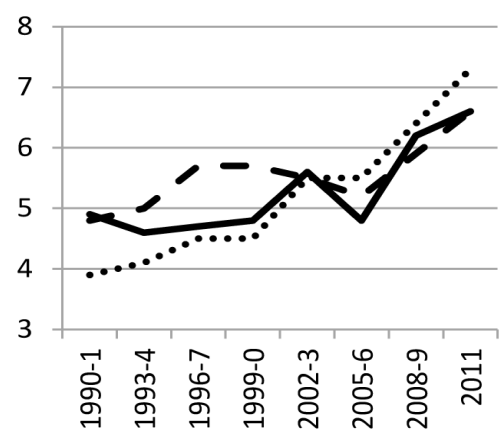

- Seg. social

-...... Educación

Sanidad

Fuente: Elaboración propia con datos de CEPALSTAT.

2.- En Chile el sistema de bienestar se construyó desde la década de 1930 sobre la base de una distribución institucional del poder de tipo conflictivo (Illanes y Riesco, 2007: 390). Así, entre 1938 y 1952 gobernó el Frente Popular con participaron de liberales, socialistas y comunistas y el apoyo de la Confederación de Trabajadores de Chile, dando impulso a la política social que se entendía como un "recurso de poder" del movimiento obrero. En 1950 se creó el Servicio Nacional de Salud Pública y en 1952 el Servicio de Seguro Obligatorio para articular las pensiones. La rápida expansión económica (crecimiento del 3,9\% anual) posterior permitió incrementar el gasto social. En la década de 1970 el sistema de protección social chileno era muy comprensivo y protegía en torno al $65 \%$ de la población, pero se caracterizaba por su complejidad y carestía, siendo además discriminatorio y regresivo a pesar de las reformas realizadas (Huber y Stephens: 2012: 90).

En 1973 el golpe militar del general Pinochet supuso un "branching point" que modifico la trayectoria de desarrollo del EB chileno con la implantación de una reforma crucial e introdujo un nuevo equilibrio consistente en la mercantilización del sistema de protección social, siguiendo un planteamiento neoliberal. Desde 1981 se estableció un nuevo sistema de pensiones obligatorio para los trabajadores, basado en un seguro pri- 
vado. En sanidad se incorporó al sistema público otro privado al que se podían vincular los asegurados en el sistema privado de pensiones. También se privatizó la educación en una mitad y se redujeron las contribuciones empresariales a la seguridad social.

Esta reforma eliminó los elementos universalistas que tenía el sistema e introdujo una gran desigualdad con un sistema clasista (Huber, 1998:168). Así, las capas con más recursos se beneficiaron de la política social del periodo, mientras que los pobres, que en 1987 eran más de la mitad de la población, no tuvieron apenas apoyo de los servicios asistenciales que estaban poco desarrollados (Illanes y Rieco, 2007: 405). Por otro lado, la privatización conllevó una redistribución del poder institucional por la introducción en la organización y gestión de los servicios de bienestar de nuevos actores privados "buscadores de rentas" muy poderosos. El movimiento obrero quedó muy debilitado por una dictadura fuertemente represiva y los trabajadores no podían ejercer una presión suficiente para cambiar el curso de la política social, ya que en torno al 50\% se encontraban en el sector informal.

La llegada de la democracia en 1989 supuso un nuevo equilibrio que promovió una reforma del sistema en sentido universalista. Sin embargo, las líneas básicas de la política económica y social neoliberal se mantuvieron por más de una década y media, ya que las reformas han estado dificultadas por las numerosas previsiones contenidas en la Constitución que daban poder de veto a las fuerzas armadas o enclaves dominados por los partidos de derecha. Por ello la reforma más importante de la última década ha sido la de la propia Constitución, y desde 2005 se han ido eliminando tales limitaciones (Huber y Stephens, 2007: 179).

Las correcciones llevadas a cabo por los gobiernos de izquierda de la Concertación de Partidos por la Democracia entre 1990 y 2010 han ido en la línea de realizar una desmercantilización de las políticas de sanidad, educación y pensiones de manera gradual y progresiva, a medida que se consolidaba la democracia, reformando el mercado de trabajo. A esto ha ayudado un crecimiento económico de más del 7\% del PNB entre 1990-1999 (y más del 4\% a partir del 2000), que ha permitido incrementar el gasto social, llegándose a duplicar en sanidad y educación en el periodo considerado (gráfico 2), si bien no han recuperado el nivel anterior al golpe de Estado en términos de porcentaje del PNB.

El mayor problema ha radicado en la reforma del sistema de pensiones, pues es difícil acceder a una pensión digna en Chile, porque una buena parte de los trabajadores no han conseguido consolidar derechos bajo el régimen de capitalización individual y han acabado dependiendo de la asistencia social (Martínez Fanzoni, 2007: 36). Por ello en 2008 la presidenta socialista M. Bachelet aprobó un nuevo programa de pensiones que orientó el sistema en un sentido universalista aunque limitado, basado en incrementar las pensiones públicas y las no contributivas ("pensión solidaria básica") y expandir la cobertura subsidiando a los que tienen sus pensiones gestionadas en el sistema privado. También desde el primer momento el gobierno del presidente Aylwin reformó el 
sistema de contratación laboral, lo que tuvo la repercusión de reducir el porcentaje de trabajo informal, como se puede ver en el gráfico 2.

Se ha logrado la universalización de la educación básica y secundaria, si bien $2 / 3$ de la educación en este nivel están en manos de la escuela privada. El mayor logro de los gobiernos de la Concertación ha sido la reducción de la pobreza, como se puede ver en el gráfico 2, y el facilitar a la población el acceso a los servicios públicos. Destaca al programa puesto en marcha por el presidente Lagos llamado "Chile Solidario", que es un programa focalizado para la lucha contra la pobreza severa. Se trata de un programa de transferencias condicionadas vinculado al ámbito educativo. También se introdujo en 2001 el seguro de desempleo, aunque ha tenido efectos muy limitados. Se ha incrementado el gasto en sanidad y educación, con programas explícitos para la mejora de servicios, como el Plan AUGE en sanidad, también impulsado por el presidente Lagos, luego ampliado por la presidenta Bachelet a partir de 2008. Otra dimensión de la política social ha sido el incremento progresivo del salario mínimo en este periodo.

GrÁFico 2: IndicAdores de Chile 1990-2011
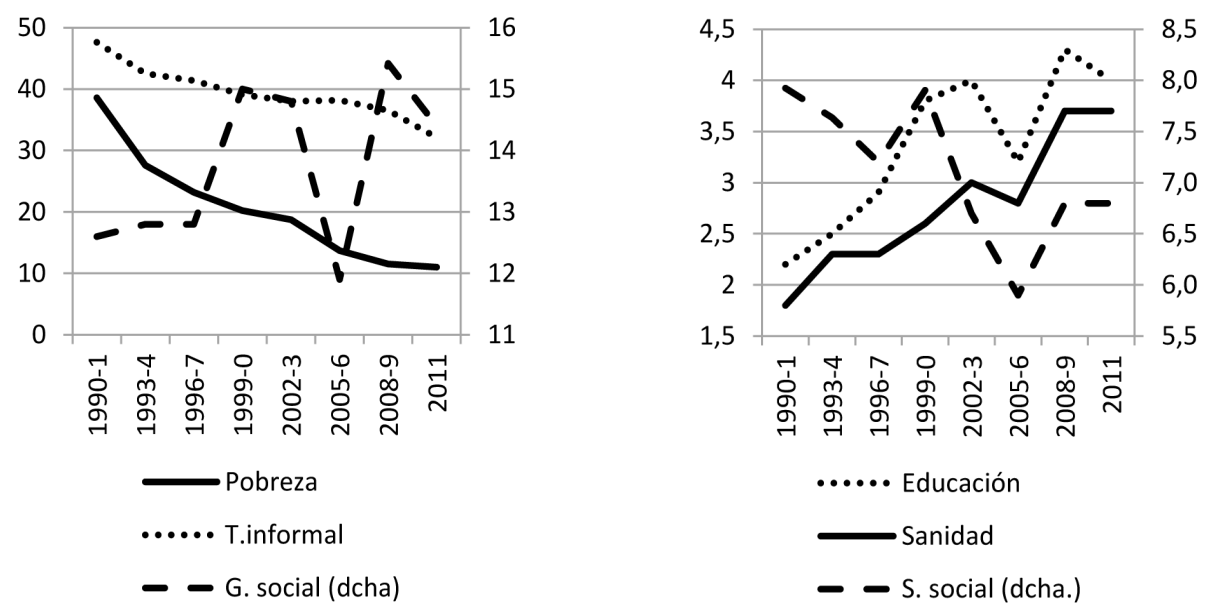

Fuente: Elaboración propia con datos de CEPALSTAT.

De acuerdo con Pribble (2013) el desarrollo del universalismo en el EB chileno con el gobierno de la Concertación de los últimos 20 años representa el proyecto de "universalismo desde arriba" llevado a cabo por unas elites reformistas tecnocráticas. Esto ha sido posible por la debilidad del movimiento obrero, el carácter electoral-profesional del partido de gobierno (la Coalición) y la fuerte competencia electoral del partido (coalición) de derechas. Además, en el gobierno de izquierda se han impuesto los sectores que han dado prioridad al control fiscal y a la estabilidad económica, pero comba- 
tiendo activamente la desigualdad y la pobreza. Así es que la reforma sanitaria se hizo posible una vez que se aseguró la salud fiscal del Estado y gracias al apoyo electoral de la población usuaria mayoritariamente del servicio público de salud. En el caso de las pensiones la reforma ha sido más difícil por la existencia del fondo de gestión de las pensiones privadas (AFP), que es en un poderoso grupo de presión que actúa en conjunción con los empresarios privados, que no tienen que pagar contribuciones en el sistema actual. Todo ello a pesar de que el sistema de pensiones privado era fiscalmente y socialmente insostenible (Huber y Bogliaccini, 2010: 648; Pribble, 2013: 73). Aunque el "universalismo desde arriba" (tecnocrático) tiene gran capacidad de maniobra por estar desvinculado de los sindicatos, que tienden a imponer criterios particularistas a las reformas, sin embargo no permite que se logre un universalismo completo, porque el partido de izquierda, al estar carente de una base de apoyo en grupos sociales, acaba por tener dificultades para defender sus reformas frente a los grupos de presión del sector privado y la coalición de derechas.

3.- En Argentina la formación del EB se inició con el Presidente J.D. Perón entre 1946 y 1955. Este tenía el objetivo de promover el desarrollo económico apoyándose en la emergente clase obrera urbana, por lo que estableció un sistema de seguridad social de inspiración bismarckiana. El resultado fue un sistema que daba una amplia protección mediante pensiones y sanidad, de carácter altamente corporativo, segmentado y desigual, basado en una fuerte influencia de los sindicatos. Se puede decir que en torno a 1980 Argentina tenía el Estado de bienestar más generoso de AL (Huber, 1998: 151), pero con graves problemas de financiación debido a la elevada evasión entre los autónomos, los retrasos de pagos de los empresarios, la inclusión de trabajadores que no hacían las contribuciones obligatorias, etc., (Barbeito y Goldberg, 2007: 192).

Argentina mostró los primeros síntomas de crisis económica en 1976, lo que llevó al poder a los militares, que trataron de introducir un nuevo equilibrio con unas políticas de corte neoliberal similares a las de Pinochet en Chile, pero debieron dejar el poder tras la guerra de las Malvinas, en medio de una severa crisis fiscal del Estado. En la nueva etapa democrática se empezó a imponer el criterio entre los distintos sectores sociales, la burocracia y los intereses del capital trasnacional, de la necesidad de llevar a cabo reformas profundas, es decir, un nuevo equilibrio, siguiendo las premisas neoliberales del Consenso de Washington. Estas se pusieron en práctica por el Gobierno de Menen (1989-99) y, en consecuencia, se abandonó el objetivo de construir un sistema de bienestar universalista. Este es, por tanto, un branching point que redireccionó la trayectoria del emergente EB.

Como resultado de la política económica neoliberal se produjo un elevado desempleo industrial, acompañado de una caída del gasto social y una reducción de la cobertura de la protección social. El efecto inmediato fue un gran incremento de la pobreza, como se puede ver en el gráfico 3, pues el EB no estaba preparado para enfrentar la situación. El gobierno de Menem también llevó a cabo una privatización de la pensio- 
nes introduciendo un sistema de tipo mixto en 1994, justificándolo en las dificultades financieras del sistema (Pribble, 2013: 150). Así, se estableció un sistema público básico obligatorio de carácter contributivo y un sistema complementario mediante la creación de las Administradoras de Fondos de Jubilaciones y Pensiones (AFJP), y los trabajadores pudieron voluntariamente mantenerse en el fondo público o pasarse al fondo privado al que iban a parar sus contribuciones. Esto tuvo la consecuencia de una reducción de la cobertura de personas jubiladas. Por otra parte los costes de gestión de los fondos fueron muy elevados, reduciendo los beneficios y, además, las crisis como la de 2001 produjeron pérdidas en las inversiones de los fondos (Barbeito y Goldberg, 2007: 198).

Con la crisis de 2001 y el crecimiento de la pobreza, un Gobierno interino de Duhalde hubo de lanzar un nuevo programa de transferencias condicionadas, el Programa de Jefes y Jefas de Hogar Desocupados que, a pesar de su escala para alcanzar un gran número de personas, pues llegó a tener 2 millones de beneficiarios, apenas tuvo efectos para combatir la pobreza y reducir el desempleo (v. gráfico 3) (Barbeito y Goldberg, 2007: 200). Este programa fue luego sustituido por tres diferentes: el Plan Familias, el Seguro de Capacitación y Empleo y la Asignación Universal por Hijo para Protección Social en 2009.

El acceso de E. Kirchner a la presidencia en 2003 introdujo un nuevo equilibro y un cambio en el path de desarrollo de la política social en un sentido universalista. Se abandonó la política neoliberal y se impulsó el intervencionismo estatal para relanzar la economía y también la seguridad social. Comenzó un periodo en el que se ha llevado a cabo una expansión de la protección social con programas de transferencias monetarias, el incremento del salario mínimo y dando apoyo a los sindicatos, lo que ha favorecido una reducción de la pobreza. Concretamente, se amplió el acceso al sistema de seguridad social en 2005 para combatir los altos índices de pobreza, por lo que pudieron acceder a las pensiones por jubilación desempleados y trabajadores del sector informal que no tuvieran suficientes años de cotización (conocido como "moratoria"). Más tarde, una nueva reforma en 2007 con el gobierno de Fdez. de Kirchner suprimió el sistema privado de pensiones (nacionalizándolo) y universalizó el público, dando protección a prácticamente rodos los ancianos tanto por la vía contributiva como por la asistencial. Sin embargo no se acabó con la segmentación histórica del mismo (Pribble, 2013: 153). Esto supuso una fuerte expansión del gasto social, en particular en seguridad social, como se puede ver en el gráfico 3. E. Kirchner también reforzó el sistema de negociación colectiva, lo que repercutió en un incremento de los salarios. Todo ello ha supuesto una fuerte reducción de los niveles de pobreza, como también se puede ver en el grafico 3 (Levitsky y Murillo, 2008: 17).

En Argentina el sistema educativo está universalizado, no así el sistema sanitario, aunque toda la población tiene derecho a ser atendida gratuitamente en los hospitales públicos. La sanidad está financiada a través de las contribuciones de empleados y trabajadores y su gestión y calidad varía en función de las distintas "Obras Sociales" 
encargadas de la misma. Son conocidos los problemas de mala gestión y corrupción que tiene, pues sus gestores, los sindicatos, las utilizan como un medio para obtener recursos (Huber, 1998: 175).

En la actualidad se dan dos situaciones que dificultan el desarrollo del EB institucional-redistributivo en Argentina. Una es la diversidad y complejidad de los programas de bienestar que dificultan el universalismo y otro es el problema de la sostenibilidad financiera del sistema (Huber y Stephens, 2012:190). Las dificultades que ha habido para universalizar completamente el sistema de protección social derivan de la naturaleza del Partido Justicialista y su incidencia en la distribución del poder institucional, ya que ha dado gobiernos de corte neoliberal como el de Menen, y de centro izquierda como los de los presidentes Kirtchner y Fdez. de Kirchner. Es un partido muy flexible que para gobernar tiene necesidad de conectar con los sindicatos de trabajadores y, al mismo tiempo, con los electores de bajos ingresos y del medio rural, por lo que ha desarrollado una relación de tipo clientelar con ellos, es decir, de cambio de votos por favores. Esto impide que el sistema se desarrolle en un sentido universalista porque los recursos se distribuyen según criterios particularistas, es decir, de "buscadores de rentas" que protegen sectores parciales. La distribución de poder que tal hecho produce es muy determinante y, así, mientras que ha favorecido la universalización en el sistema educativo, ha impedido que esto se realice en sanidad, pues el control de las "Obras Sociales" por los sindicatos dificulta enormemente su reforma, ya que genera una resistencia de tipo corporativo (Pribble, 2013: 137).

GrÁFico 3: IndicAdores de ARgEntina 1990-2011
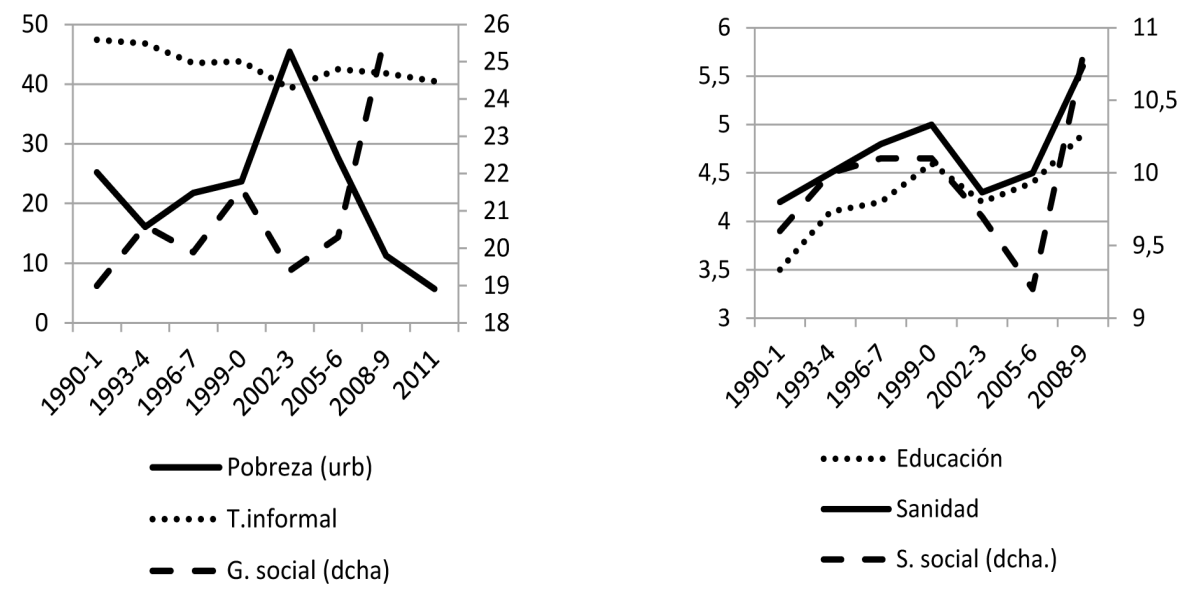

Fuente: Elaboración propia con datos de CEPALSTAT. 
4.- En Brasil la trayectoria del EB ha quedado marcada por su origen con la dictadura militar de Getulio Vargas. En el Estado Novo fundado en 1937 se configuró una estructura institucional de distribución del poder corporativista con el objetivo de atraer y controlar el movimiento obrero emergente. Se estableció una organización sindical nacional dirigida desde el Gobierno vinculada a la gestión de un sistema de seguridad social, creado exclusivamente para los trabajadores urbanos. Más tarde el sistema fue reformado en 1964 por un nuevo régimen militar que redistribuyó el poder institucional siguiendo criterios tecno-burocráticos. Se unificó la gestión de la seguridad social aboliendo la representación sindical en su administración. Además, en 1971 se estableció un sistema de protección que garantizaba un mínimo de renta y acceso al sistema de salud pública a la población rural (FUNRURAL). Como consecuencia de todo ello a principios de los 80 el sistema cubría en torno al 75\% de la población activa (Draibe, 2007: 259). Sin embargo el gasto social era más bajo que en otros países de AL, excluía a los trabajadores del sector informal y, además, las prestaciones en el ámbito rural eran muy bajas (Huber, 1998: 150).

En el momento de la recesión entre 1981-83 el gobierno militar había iniciado un proceso de apertura democrática que culminó en una nueva distribución del poder en 1985. En esta nueva situación de equilibrio los políticos conservadores habían establecido lazos clientelares con sectores de la población, y los políticos de izquierda defendían un enfoque socialdemócrata de la política social; además, se estaba organizando un sindicalismo independiente del Estado, encarnado políticamente en el Partido de los Trabajadores (PT). Por esto las políticas neoliberales no calaron en Brasil de la misma manera que en otros países de AL y no se produjo un branching point con cambio de trayectoria en la configuración del EB. La reforma económica fue gradual, sin el coste social de una grave desindustrialización, aunque la crisis afectó al sistema de seguridad social al igual que en otros países por la caída del empleo y la bajada de los salarios.

El gobierno democrático reformista de Sarney inició una reorientación de la trayectoria del EB al favorecer la universalización de la política social, haciéndola más inclusiva y reduciendo privilegios existentes. Sin embargo, los sindicatos de trabajadores urbanos ofrecieron gran resistencia a las reformas, que quedaron frenadas finalmente por dificultades financieras. La sanidad, sin embargo, quedó universalizada a partir de 1987 mediante el Servicio Nacional de Salud, pero con un sistema fragmentado.

El presidente Cardoso (1995-2002), además de lidiar con la crisis fiscal del Estado, trató de sacar adelante una agenda reformista que pretendía la universalización de los servicios sociales públicos, introducir programas de empleo y avanzar en la lucha contra la pobreza (Draibe, 2007: 266). Como su partido solo contaba con un pequeño número de escaños en las cámaras, se orientó a la construcción de una coalición parlamentaria, que finalmente tuvo dificultades para llevar adelante el programa de reformas por la falta de disciplina de partido (Huber y Stephens, 2012: 171). La reforma más importante de esta etapa se aprobó en 1998 con el objeto de controlar el déficit de la 
seguridad social. Introdujo medidas como una pensión mínima para empleados públicos y la redefinición de los subsidios y la edad de jubilación. También trató de reforzar la base financiera del sector de la sanidad, ampliando su impacto redistributivo. En el ámbito educativo se incrementó y descentralizó el gasto en educación primaria a partir de 1998. También se creó un Fondo de Pobreza en 2000, que supuso un cambio en la tradicional política asistencial.

Con los gobiernos de izquierda del PT de L.I. de Silva (Lula) entre 2003-2010 y de D. Roussef a partir de 2011, se estableció un nuevo equilibrio institucional que refuerza el proceso de construcción de un sistema de bienestar universalista en la trayectoria de formación de un EB institucional-redistributivo. Las principales reformas del gobierno de Lula han sido la reforma del sistema de pensiones, la expansión del programa Bolsa Familia y un significativo incremento del salario mínimo. La reforma de las pensiones tuvo un carácter claramente redistributivo, pues se aprobaron topes a las cuantías y se facilitó al acceso a ellas de los trabajadores del sector informal. En educación y sanidad se continuaron las reformas iniciadas en la fase de Cardoso. En sanidad destacó el desarrollo de la sanidad preventiva y primaria y el establecimiento de farmacias rurales. Una de las grandes reformas en la política social de esta etapa es el programa que ofrece ayuda monetaria a los pobres llamado "Bolsa Familia" (sucesor del programa "Hambre Cero"). Se trata de una política focalizada de lucha contra la pobreza al que han accedido más de 12 millones de familias y que en 2011 ha llegado al 26\% de la población (The Guardian, 21 de febrero de 2011). Es un programa de gran éxito, como se puede comprobar en el gráfico 4, por la reducción de la pobreza que ha producido.

El PT ha sufrido una transformación a lo largo de los años, que ha producido una modificación en la distribución de poder institucional. Cuando llegó al gobierno operaba como un partido orientado hacia la coordinación de los electores, basado en la movilización social y el apoyo de numerosos grupos como los sindicatos, los católicos progresistas y los movimientos sociales. Con los años el PT se ha transformado en un partido de carácter electoral-profesional, centralizado y estructurado desde la burocracia estatal y local, en manos de una elite tecnocrática que lo ha orientado a la competición electoral (Daribe, 2007: 263).

Como el PT en la etapa inicial era una coalición que se basaba en la negociación entre los diversos grupos de apoyo, los procesos de reforma universalista se hicieron muy difíciles, porque los grupos planteaban demandas de tipo particular a la acción de gobierno, con un comportamiento de "buscadores de rentas". Así, la reforma de pensiones del sector público del primer gobierno de Lula (en 2003) acabó siendo condicionada por los sindicatos del sector público ligados a dicho partido. La potencialidad reformista, sin embargo, se ha reforzado cuando el partido se transformó en uno de base profesional-electoral que, en lugar de tratar de estrechar vínculos con los sectores sociales, ha seguido un planteamiento programático limitándose a buscar apoyo electoral entre los sectores de población beneficiados (Pribble, 2013: 183). 
GrÁFICO 4: INDICADORES DE BRASIL 1990-2011
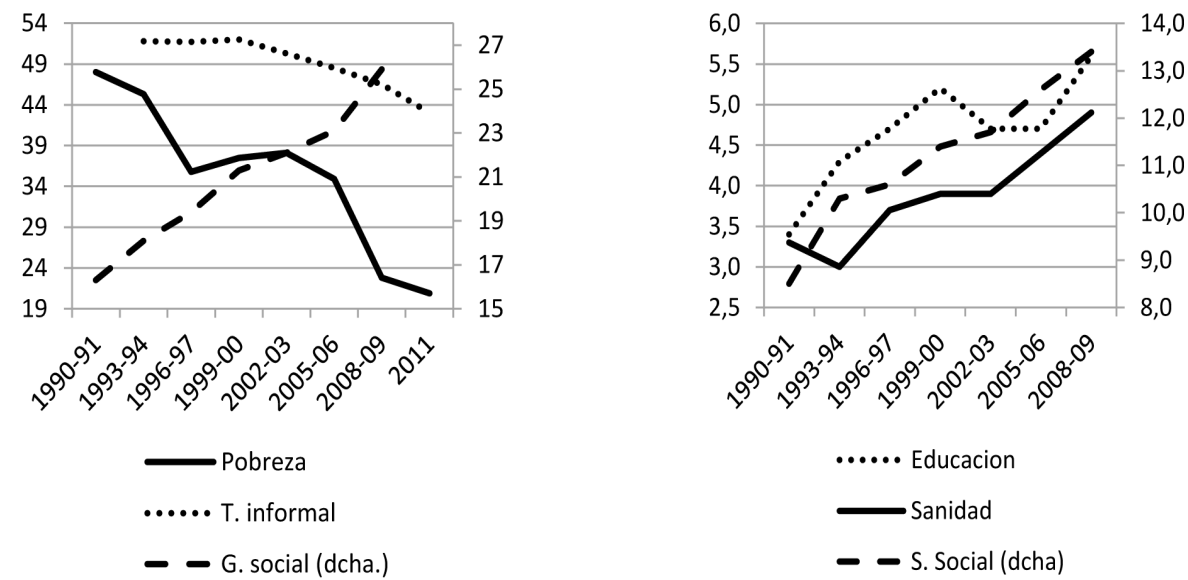

Fuente: Elaboración propia con datos de CEPALSTAT.

5.- Uruguay ha sido el país de AL que antes ha desarrollado una política social de carácter universalista. Su origen está vinculado a la construcción del Estado-nación por J. Batlle y el Partido Colorado en los años de 1914-19, cuando se estableció un sistema de pensiones de tipo contributivo, además de ayudas a la indigencia, que tenía un carácter avanzado en la época. También en estos años se implantó un sistema educativo público como instrumento de la construcción de la identidad nacional (Bonino, Kwon y Dutrey, 2007: 219). La sanidad quedó en manos de unas mutualidades, los Institutos de Asistencias Médica Colectiva (IAMC), que utilizan los hospitales públicos bajo contrato. En 1945 el Gobierno formalizó este sistema sanitario público-privado en el que la afiliación es obligatoria para los trabajadores. También en esta época se establecieron las pensiones no contributivas, un programa de ayudas familiares y el seguro de desempleo. Así el sistema de pensiones quedó prácticamente universalizado, aunque de base corporativa y mal financiado (Bucheli, Ferrera, Forteza y Rossi, 2006: 2; Huber y Stephens, 2012: 87). En 1969 se creó el Banco de Previsión Social (BPS) para administrar las pensiones.

En el periodo de dictadura militar entre 1973 y 1985 apareció un nuevo equilibrio y se produjo una redistribución de fuerzas, con lo que el EB uruguayo comenzó a sufrir un proceso de declive debido a los efectos de la crisis económica y a las medidas neoliberales adoptadas. Sin embargo, esto no se tradujo en un cambio de trayectoria en el desarrollo del EB. Solo se produjo un deterioro financiero que acarreó una reducción de los beneficios de la seguridad social, así como del gasto en sanidad y educación, lo que afectó a la calidad de los servicios. El presupuesto público, por otra parte, se convirtió en el mayor contribuyente de la seguridad social, lo que hizo engrosar el déficit público, 
convirtiéndose la reforma de la seguridad social en la mayor preocupación de todos los gobiernos a partir de 1984 (Huber y Stephens, 2012: 88).

En 1989 con un gobierno el Partido Colorado se aprobó por referéndum indexar las pensiones a los sueldos del sector público lo que, debido a la amplia cobertura que estas ofrecían y al envejecimiento de la población, produjo un fuerte incremento del gasto de la seguridad social en el comienzo de los 90 (ver gráfico 5) y también del déficit de la seguridad social. La reforma del sistema de pensiones se realizó finalmente en 1995, estableciéndose un nivel básico gestionado por el sistema público BPS y otro complementario gestionado por aseguradoras privadas (AFAP) para los niveles de renta medios y altos. Las contribuciones empresariales solo financian el sistema público. También se amplió el periodo de cotización para acceder a ellas. El pilar no contributivo se mantuvo, aunque se aumentó la edad para acceder al mismo a 70 años.

La crisis de la deuda llevó al país a una recesión y a una fuerte crisis económica en 2001. Se redujo el empleo en el sector formal con un fuerte aumento de la pobreza, que a su vez forzó un crecimiento de la emigración de la población. Esto fue debido en parte a que el seguro de desempleo solo cubre seis meses y solo alcanzó al 17\% de los desempleados. En 2004 llegó al poder la coalición de izquierdas del Frente Amplio, al mismo tiempo que comenzó la recuperación económica. Ello supuso un nuevo equilibrio que permitió reorientar la trayectoria de la política social en un sentido universalista. El FA se encontró con el legado de que la intervención del Estado no había sido reducida tanto como en otros países y que las tesis neoliberales estaban menos arraigadas, por lo que pudo llevar a cabo un amplio programa de reformas (Bonino, Kwon y Dutrey, 2007: 221). Su primera iniciativa en política social fue la introducción de un plan de emergencia social, el PANES, que era un programa de transferencias para familias en situación de pobreza. Este tuvo una rápida incidencia, como se ve en el gráfico 5. El programa fue sustituido en 2007 por el "Plan Equidad" que ha institucionalizado una ayuda para familias de bajos ingresos y ha reducido la edad para acceder al sistema de pensiones no contributivas, ampliando las ayudas que están establecidas desde 1943. El plan está vinculado con la escolarización de los niños.

La reforma del FA en pensiones para combatir el corporativismo se ha basado en la implantación de un impuesto que grava las pensiones más altas y, gracias al aumento del número de contribuyentes, se ha reducido el déficit que generaban, pudiéndose incrementar las pensiones en los últimos años. La ratio de cobertura (beneficiarios/ contribuyentes) de las pensiones en 2002 es del 1,25 (Bonino, Kwon, y Dutrey, 2007: 223). En sanidad el FA llevó a cabo una reforma en 2007 para mejorar la calidad de la atención sanitaria asistencial a través del Sistema Nacional Integrado de Salud (SNIS). El FA ha unificado la financiación sanitaria, pero no ha modificado su gestión, que está en manos de las IAMCs que se financian desde un fondo de la seguridad social. El sistema ofrece una protección sanitaria casi universal con servicios de la misma calidad a todos los ciudadanos (Huber y Stephens, 2012: 185). Como se puede ver en el gráfico 
5, se ha incrementado el gasto público en sanidad, que pasó del 3,6\% del PIB en 2005 al 5,3\% en 2011, y en el ámbito educativo, particularmente el destinado a la asistencia preescolar, pasando el gasto del 3,6\% del PIB en 2001 al 5,3\% en 2011. Uruguay es el primer país que garantiza a cada alumno un ordenador portátil. El FA ha intervenido también para facilitar la formalización de trabajadores no registrados en la seguridad social.

La institucionalización del EB universalista en Uruguay, en particular desde los años 90, responde a una particular distribución del poder. De acuerdo con Pribble (2013: 26) esta refleja la creciente competencia partidista entre el P. Colorado y el F. Amplio y la naturaleza de este último, que es un partido (coalición) orientado a la "coordinación de electores", con los que tiene estrechas relaciones que van más allá del periodo electoral. Señala esta autora que, gracias a las políticas del FA, Uruguay representa actualmente un modelo de desarrollo del EB universalista (institucional-redistributivo) en AL. Este está basado en el apoyo que recibe desde la base social (de abajo hacia arriba) y es debido a la construcción de una coalición que requiere la negociación entre grupos sociales. En el otro lado de la balanza pesa la presión de los intereses particulares de "buscadores de rentas", las IAMCs, en la formulación de las políticas, lo que acaba dificultando la construcción de un modelo completamente universalista y promoviendo un modelo mixto.

GrÁFico 5: IndicAdores De URUGUAy 1990-2011
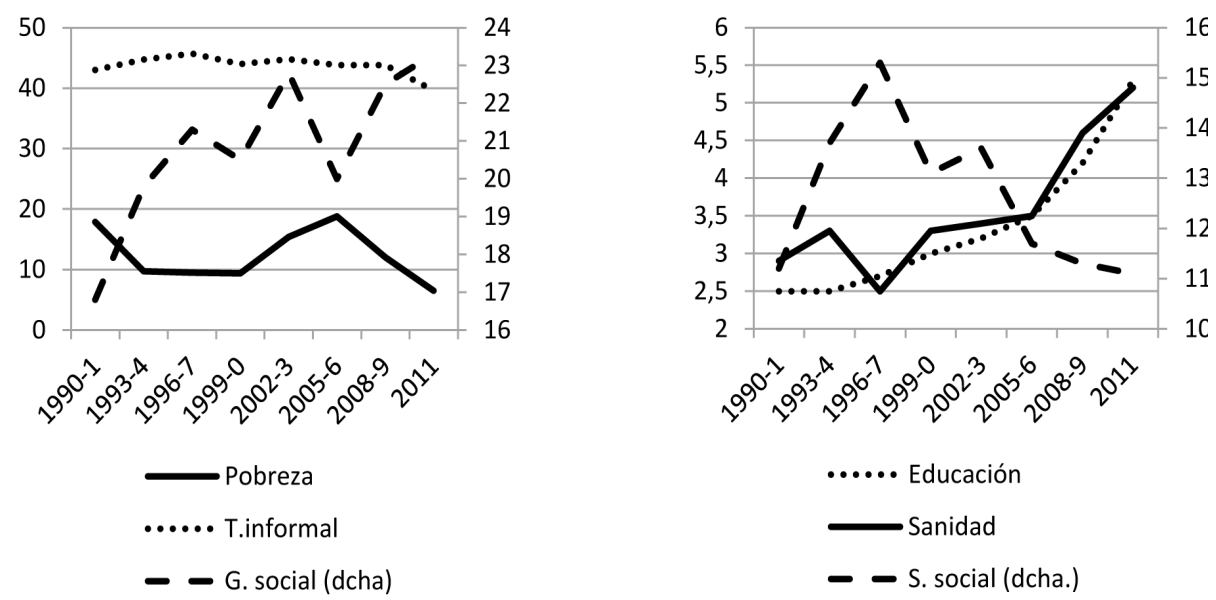

Fuente: Elaboración propia con datos de CEPALSTAT. 


\section{Conclusiones}

De tal análisis realizado se pueden sacar conclusiones en tres vertientes. Una en la perspectiva de las trayectorias seguidas incluyendo las reformas más recientes, otra en relación con la estructura de los equilibrios político-institucionales que se han ido fraguando y, finalmente, en relación con la gradualidad de las reformas que tiene en cuenta la distribución de poder que las impulsa.

En la primera perspectiva en este trabajo se ha identificado claramente que todos los casos siguen una trayectoria corporativa desde su origen, estratificando el sistema de seguridad social. Es imaginable que, de no haberse producido la crisis del modelo de "sustitución de importaciones" a comienzos de los 80 , las altas cotas de desarrollo y universalización de la política social logradas hubieran facilitado un proceso reformista y el salto hacia un EB institucional-redistributivo. La implantación de políticas neoliberales del Consenso de Washington ha sido un branching point en el que se ha tratado de reorientar la trayectoria inicial hacia un modelo de tipo residual, con más profundidad en los casos Chile y Argentina que en los otros casos considerados. La llegada de los gobiernos de izquierda a todos los países con el cambio de siglo ha introducido una clara rectificación y una reorientación de la trayectoria hacia un modelo de EB institucional-redistributivo. La nueva expansión económica de los comienzos del siglo XXI ha facilitado el desarrollo del nuevo path universalista.

Al considerar los distintos equilibrios se pueden destacar los factores exógenos en los procesos de reforma. El primer equilibrio general se dio con la formación del modelo corporativo. A grandes rasgos se puede decir que hasta la crisis de los años 80 la expansión económica facilitó la industrialización y la urbanización de las sociedades, y con ello la aparición del movimiento obrero organizado, junto a nuevas elites empresariales y clases medias y unas burocracias públicas ligadas a la propia intervención estatal. Todo ello impulsó el desarrollo de la seguridad social, la sanidad y la educación, si bien con grandes deficiencias en el ámbito de la financiación y siguiendo un patrón corporativo que excluía a los trabajadores del sector informal, por tanto, no redistributivo. El segundo equilibrio general surgió con los gobiernos neoliberales, que llevaron a la práctica una política económica marcada por la crisis de la deuda y las imposiciones de las organizaciones financieras internacionales como el FMI, el Banco Mundial o el Banco Interamericano de Desarrollo. La crisis económica llevó en unos casos a la implantación de dictaduras militares (Chile, Argentina, Uruguay) y en otros casos, como en Argentina, a gobiernos elegidos que han trabajado para configurar un Estado de bienestar residual, si bien con grandes deficiencias en la configuración del "safety net", lo que produjo un grave incremento de la pobreza. Pero el nuevo equilibrio neoliberal no modificó sustancialmente el path corporativo inicial en Costa Rica, Brasil o Uruguay. El tercer gran equilibrio se ha producido con la llegada de los gobiernos de izquierda en el cambio de siglo, que ha reforzado la intervención del Estado en un sentido universalista de carácter institucional-redistributivo 
en el marco de un planteamiento económico neo-desarrollista. Sin embargo estos gobiernos han mantenido pautas de la reforma liberal como la gestión privada de pensiones en Chile, también la gestión privada de la sanidad en Uruguay y Argentina y, en general, los programas de lucha contra la pobreza vía transferencias condicionadas, aunque mejorados. Estos han sido particularmente relevantes en Brasil, Uruguay y Argentina.

En la perspectiva de la gradualidad de las reformas y considerando los factores endógenos influyentes, primero cabe decir que la política social se ha configurado como un recurso de los distintos grupos que se han ido incorporando al sistema de protección social. De ahí el fuerte carácter corporativo estratificado que ha tenido históricamente el modelo de EB en AL. En él han operado claramente los grupos de "buscadores de rentas" que, bien han construido su nicho de protección particular, bien han tomado el control de la gestión de los servicios. Ejemplo de lo primero son los sindicatos de Argentina mediante las Obras Sociales, y de Uruguay mediante las IAMCs. Ejemplo de lo segundo es la fuerte industria de carácter privado para la provisión de los servicios sociales establecida en la etapa neoliberal en Chile en el ámbito de las pensiones y la sanidad. Estos son elementos que dificultan el proceso de institucionalización universalista.

Por otra parte, las reformas producidas en el siglo XXI con los gobiernos de izquierda muestran que el Estado de bienestar es un recurso de poder para los trabajadores. Así se desprende de la acción de los gobiernos de izquierda, que han construido una coalición reformista en pro de la universalización de la política social. En todos los casos considerados salvo Argentina el proceso de reforma universalista ha sido impulsado gracias a la fuerte competición electoral basada en la polarización partidista (o de coaliciones). Han tenido más éxito en la universalización aquellos gobiernos que se han apoyado en partidos de "coordinación de electores" y en negociaciones entre grupos sociales de base popular como en Uruguay y Brasil.

CuAdro 2: TABla RESUmen

\begin{tabular}{lccccc}
\hline & Costa Rica & Chile & Argentina & Brasil & Uruguay \\
\hline Corporativismo histórico & SI & SI & SI & SI & SI \\
Reforma neoliberal & Débil & Fuerte & Fuerte & Débil & Débil \\
Gobierno de Izquierda - siglo XXI & SI & SI & SI & SI & SI \\
Universalización alcanzada & Medio-alto & Medio-alto & Medio-alto & Medio & Medio \\
Importancia Transferencia monetarias & Media & Media & Medio-alta & Alta & Alta \\
Gestión privada de servicios sociales & NO & SI & SI & NO & SI \\
\hline
\end{tabular}

Fuente: Elaboración propia. 
Por último, cabe señalar que en el juego de coordinación al que responde la política social, a diferencia de las reformas de la etapa corporativa inicial, las reformas del siglo XXI configuran un juego cooperativo porque son redistributivas y combaten eficazmente la pobreza. En todos los casos se observa un esfuerzo en el gasto sanitario, que es altamente redistributivo, $\mathrm{y}$ en el gasto en educación para el desarrollo del capital humano que, además de combatir la pobreza, es un factor determinante para facilitar el desarrollo del mercado de trabajo formalizado, pieza clave a su vez para asegurar el EB institucional-redistributivo del futuro en AL.

\section{Bibliografía}

Barahona, M. , L. Güendel, y C. Castro (2007): "Social Policy and Social Reform "Costa Rican Style": A Paradigmatic Case of Heterodoxy in the Context of a Peripheral Economy", en Manuel Riesco (ed.), Latin America. A New Developmental Welfare State Model in the Making?, Londres, Palgrave, UNRISD, pp. 327-277.

Barbeito, A. y L. Goldberg (2007): "Social Policy and Economic Regime in Argentina: Crisis and Retrenchment of Social Protection", en Manuel Riesco (ed.), Latin America. A New Developmental Welfare State Model in the Making?, Londres, Palgrave, UNRISD, pp.187-216.

Bonino, M., H. Kwon y A. Dutrey (2007): "Uruguay's Social and Economic Challenges and Its Policy Responses", en Manuel Riesco (ed.), Latin America. A New Developmental Welfare State Model in the Making?, Londres, Palgrave, UNRISD, pp. 217-238.

Buchelli, M. et al. (2006): "El Acceso a la Jubilación o Pensión en Uruguay: ¿Cuántos y Quiénes lo Lograrían?", Documentos de Trabajo 2006/01, Dpto. de Economía de la Fac. de CC. Sociales de la República de Uruguay.

Carrera, M. y R. Muñoz de Bustillo (2009): "El reto de la pobreza y la desigualdad en America Latina", Sistema, 208-209, pp.73-95.

CARRERA, M. y J.I. ANTÓN (2008): "Las relaciones entre equidad y crecimiento y la nueva agenda para América Latina", América Latina Hoy, 48, pp. 43-66.

CEPAL (2012): Panorama social de América Latina, Santiago de Chile, Naciones Unidas.

Draibe, S. (2007): “The Brazilian Developmental Welfare State: Rise and Perspectives”, en Manuel Riesco (ed.), Latin America. A New Developmental Welfare State Model in the Making?, Londres, Palgrave, UNRISD, pp. 239- 281.

Draibe, S. y M. Riesco (2007): "Latin America: Modernizing and the Threshold of the Twenty-First Century", en Manuel Riesco (ed.), Latin America. A New Developmental Welfare State Model in the Making?, Londres, Palgrave, UNRISD, pp. 21-116.

Eriksson, L. (2011): Rational Choice Theory. Potential and Limits, Londres, Palgrave and Macmillan. 
EspinA, A. (2008): "Modernización, estadios de desarrollo económico y regímenes de bienestar en América latina", Documento de trabajo 28, Madrid, Fundación Carolina- CeALCI.

EsPing-Andersen, G. (1990): The Three Worlds of Welfare Capitalism, Princeton, Princeton University Press.

FilgueirA, F. (2007): "Cohesión, riesgo y arquitectura de protección social en América Latina", Politicas sociales 135, CEPAL/Naciones Unidas.

Gough, I. et al. (2004): Insecurity and Welfare Regimes in Asia, Africa and Latin America: Social Policy in Development Contexts, Cambridge, Cambridge University Press.

Gough, I. y G. Therborn (2010): "The Global Future of Welfare States”, en Francis Castles et al., The Oxford Handbook of the Welfare State, Oxford, Oxford University Press, pp. 703-720.

HALl, P. A. (2012): "Historical Institutionalism in Rationalist and Sociological Perspective", en James Mahoney y Kathleen Thelen (eds.), Explaining Institutional Change. Ambiguity, Agency and Power, Cambridge, Cambridge University Press, pp. 204-224.

Hindmoor, A. (2006): Rational Choice, Londres, Palgrave.

Huber, E. (1998): "Options for Social Policy in Latin America: Neoliberal versus Social Democratic Models", en Gosta Esping-Andersen (ed.), Welfare States in Transition, Londres, SAGE, pp. 141-192.

Huber, E. y J. Bogliaccini (2010): "Latin America", en Francis Castles et al., The Oxford Handbook of the Welfare State, Oxford, Oxford University Press, pp. 644-655.

Huber, E. y J.D. Stephens (2012): Democracy and the Left. Social Policy and Inequality in Latin America, Chicago, The University of Chicago Press.

Illanes, M.A. y M. Riesco (2007): "Developmentalism and Social Change in Chile", en Manuel Riesco (ed.), Latin America. A New Developmental Welfare State Model in the Making?, Londres, Palgrave, UNRISD, pp. 378- 424.

KuRTz, M.J. (2002): "Uderstanding the Third World Welfare State after Neoliberalism", Comparative Politics, 34 (3), pp. 293-313.

Levitsky, S. y M.V. Murillo (2008): “Argentina: from Kirchner to Kirchner”, Journal of Democracy, 19, pp.16-30.

Mahoney, J. y K. Thelen (2012): “A Theory of Gradual Institutional Change”, en James Mahoney y Katheleen Thelen (eds.): Explaining Institutional Change. Ambiguity, Agency and Power, Cambridge, Cambridge University Press, pp. 1-37.

Martinez Franzoni, J. (2007): "Regímenes del bienestar en América latina", Documento de trabajo 11, Madrid, Fundación Carolina-CeALCI.

Milanovic, B. y R. Muñoz de Bustillo (2008): La desigualdad de la distribución de la renta en América Latina: situación, evolución y factores explicativos", América Latina Hoy, 48, pp.15-42. 
NoRTH, D.C. (1990): Institutions, institutional change and economic performance, Cambridge, Cambridge University Press.

Mesa-Lago, C. (1983): "Social security and extreme poverty in Latin America", Journal of Development Economics, 12, pp. 83-110.

Mesa-Lago, C. (2008): "Un reto de Iberoamérica en el siglo XXI: la extensión de la cobertura de la seguridad social", América latina Hoy, 48, pp. 67-81.

Ostrom, E. (1995): "New Horizons in Institutional Analysis", American Political Science Review, 89 (1), pp. 174-178.

Pierson, P. (2000): "Increasing Returns, Path Dependence, and the Study of Politics", American Political Science Review, 94 (2), pp. 251-267.

Pribble, J. (2013): Welfare and Party Politics in Latin America, Cambridge, Cambridge University Press.

Riesco, M. (ed.) (2007): Latin America. A New Developmental Welfare State Model in the Making?, Londres, Palgrave, UNRISD.

Riesco, M. (2009): "Latin America. A New Developmental Welfare State Model in the Making?”, International Journal of Social Welfare, 18, pp. 22-36.

SÁnchez De Dios, M. (2001): "Estudio comparado de path dependence del Estado de bienestar en los casos de USA Suecia y España”, Revista de Estudios Políticos, 12, pp. 95-128.

SÁnchez de Dios, M. (2013): Politica comparada, Madrid, Síntesis.

Shepsle, K.A. (2008): "Rational Choice Institutionalism”, en R.A.W. Rhodes, Sarah Binder y Bert A. Rockman (eds.), The Oxford Handbook of Political Institutions, Oxford, Oxford University Press, pp. 23-38. 